\title{
Variationist Perspective on the Role of Social Variables of Gender and Familiarity in L2 Learners' Oral Interviews
}

\author{
Mohiadin Amjadian \\ Kurdistan Medical University, Sanandaj, Iran \\ Email: mohiadin72@yahoo.com \\ Saman Ebadi \\ Allameh Tabatai'e University, Tehran, Iran \\ Email: Samanebadi@gmail.com
}

\begin{abstract}
This study investigated the effects of candidates' gender and familiarity with the interviewers on their language variation in oral interviews. For this variationist investigation, 60 university students comprising both males and females were randomly assigned to groups of familiar and unfamiliar with the interviewers. Then, they were interviewed using IELTS interview framework with some modifications .Three linguistic variants, i.e. "to be" contractions, /th/ pronunciations and the use of "he and she" interchangeably were extracted from the data and transcribed for the analysis. Then, they were analyzed using descriptive procedures through tests of frequencies in SPSS software. The results indicated that acquaintanceship with the interviewer might affect speech study of the subjects, the subjects with the unfamiliar interviewer trying to be more formal than the subject with the familiar interviewer. The findings also revealed that candidates' gender affected their use of the speech variants .In fact, the speech styles of males and females were significantly different with the females being more sensitive and conservative with their language behavior in the presence of an unfamiliar interviewer. We can claim that language variation among the candidates is affected by social factors like the sex of interviewees and their familiarity with the interviewers in L2 settings.
\end{abstract}

Index Terms - language variation, oral interview, social variables gender, familiarity

\section{INTRODUCTION}

The recent research into oral language interviews has indicated that interviewees vary considerably from each other in relation to their oral performance. A key issue arising from such findings is why interviewees' linguistic behavior in interview situation with non-interview situation vary from each other. Different factors might affect this phenomenon, among which, are the interviewers' characteristics like sex, level of education, social class and familiarity or unfamiliarity with the interviewers.

Various theories have been proposed to account for this phenomenon. These theories can be divided into two general types: The first one includes what Tarone (1995) calls inner processing theories, which draw upon research in various areas of psychology. Thus, this theory seeks to explain variation primarily as the result of psycho linguistic processes of various kinds. The second type, called sociolinguistic and discourse theories, attempts to relate variation to social and functional causes. Thus the cause of interlanguage variation in this group of theories is related to such external social factors like the characteristics of the interviewer or interlocutor, the familiarity of setting and social norms and the communicative pressure placed on the speaker to perform. The number of studies focusing on the effects of social and external factors like interviewers' characteristics and their effects on the oral performance of the subjects is relatively small, especially in our country, but in the area of the influence of sex, background knowledge and L1 on the oral performance of different subjects, there is plenty of research (e.g. O'loughlin, 2002; Tannen 1990;). In referring to the potential effects on performance of qualities of the interviewers, relative to the same qualities in the candidates, McNamara (1996) is echoing Porter's (1991a) suggestion that, what he referred to as affective factors may be responsible for systematic and significant variation in the linguistic performance of test candidates. While McNamara (1996) essentially argues for a move toward a more socio-interactional view of performance, O'Sullivan (2000) suggests that, it might best be viewed from what he refers to as a socio-cognitive perspective, in which the cognitive processing of certain kinds of information is recognized as being socially driven . In this perspective, O'Sullivan like McNamara, sees oral performance as being affected by a number of factors related to the interviewer.

In this study, some linguistic items were transcribed from the data and their possible variation under the effects of the candidates' gender and their acquaintanceship with the interviewers were investigated. One reason to do this was, to see if there was any relations between speech variations of the candidates and their gender and familiarity with the interviewers. In other words, to investigate how the language of the interviewees might vary from one group to the next 
under the effects of the social variables (sex of the subjects and their acquaintanceship with the interviewer. The researchers studied the performance of the learners concerning their variable use of certain linguistic items in their oral productions including: Variable use of he/she interchangeably, "to be" present contractions (e.g., I'm, we're) and different pronunciation of $/ \mathrm{th} /$ including $/ \Theta /, \mathrm{s} /$ and $/ \mathrm{t} /$ by the subjects during their performance, as the criteria of their speech variation which have not been investigated in the previous studies.

\section{REVIEW OF RELATED LITERATURE}

\section{A. Familiarity and Gender in Oral Interviews}

A number of researchers distinguish between test features which are irrelevant to the ability which is being measured and those which are relevant to that ability (Porter and Shen Shu Hung, 1991; O'sullivan and Porter, 1995; O'Sullivan 2000). O'Sullivan's (2002) study explored the possible effect of pair-task performance of test-takers' familiarity with their partner and concludes that learners vary in their oral performance when interacting with familiar or unfamiliar speakers. He did the research with 32 Japanese students and maintained that the results might not be generelizable to other contexts. In another study Porter and Shen Shu Hung, 1991; O'sullivan and Porter, 1995; O'Sullivan 2000). O'Sullivan' s (2002) investigated the effect of gender on oral proficiency interview performance. Twelve Japanese learners were interviewed, once by a man and once by a woman. Video tapes of these interactions were scored by trained examiners. Comparisons of the scores indicated that, in all but one case the learners performed better when interviewed by a woman, regardless of the sex of the learners. Analysis of the learners' interviews indicated systematic gender differences, with producing more accurate language by the females. Porter (1991 a) examined the oral performance of thirteen Arab learners by known and unknown interviewers and found no evidence to support his hypothesized interlocutor-acquaintanceship effect. In fact, acquaintanceship with the interviewers seemed not to play a significant role in the candidates' performances. Cholewka (1997) investigated the linguistic behavior of adult second language learners in an oral interview situation. The subjects in this study were six ESL learners (one female and five male) with the same first language. An oral interview conducted twice with a four-day interval, by two different interviewers. The findings of the study revealed that, in unfamiliar setting in an oral interview situation with unknown interlocutors, ESL learners revert to their native language and produce lower level of oral proficiency in the test. This finding suggests that, a task in an unfamiliar real-life situation may elicit significantly higher proportion of language transfer errors than the same task performed in a familiar environment. Most of the reported studies on L2 learners' oral performances are based on SLA views and the analysis of the results of oral interview raw scores. We argue that linguistic variation in oral interviews might be more sensitive to the candidates' language variability and their probable performance variations caused by social factors such as their sex, social status, ... than their raw scores in oral interview tests. Therefore, this study adopts variationist perspective for the method and data analysis in order to get a more comprehensive impression of the candidates' linguistic behavior.

\section{B. Variationist Perspectives on the Oral Performance of L2 Learners}

To investigate the possible effects of the interviewees' gender and their acquaintanceship with the interviewers, on the linguistic variation of the candidates, the researchers used variationist perspective (sociolinguistic view).

In sociolinguistic view of studying oral interviews, the main goal is to make the candidates produce some natural sample of the language in a real context, and variation of language is studied instead of testing its correctitude or ranking the candidates as novice, good etc (Tarone and Liu. ,1989). Young (1988) states that variation is an accepted fact of interlanguage and one of the most pressing problems for second language acquisition is how to describe and explain the highly variable speech of 12 learners. This variation of speech, as Young (1986) explain, is under the effects of the identity of the interlocutor as a member of the learners in-group which affects the speech of learners at all levels of oral proficiency in the second language Variation theory is the attempt on the part of a number of linguists to develop linguistic theory in such a way that it can account for variation and change as going on and observable phenomenon (Fasold, 1989). It reveals that the linguistic environment around an element undergoing variation systematically affects the frequency which each variant might have. However, the social status of the subjects are factors which might influence the frequency of the variants and their occurrence in language learning settings as well. Although some researchers like Gregg (1991) argues that variation is a performance factor and it is not related to the learners' competence so it is not the concern of second language acquisition theorists, Tarone and Liu (1989) focus on external interactions an L2 learner performance in a variety of social contexts and argue that data on variability are crucial to explaining the mechanism of SLA. Different studies have been done on the language variation and oral performance of L2 learners, investigating the possible effects of various factors on them.

Liu (1991) argues that the external social interactions of a learner seemed to differently activate internal acquisition processes. He conducted a two year longitudinal study of a Chinese boy when he was 5 till 7 years old. The boy acquired English in four interactional contexts; 1) Interacting with preschool peers 2) interacting with his teachers in primary school 3) interacting with primary school peers 4) interacting with the adult researchers. The boy's interactions in these four settings were analyzed and the results indicated that the boy's performance in general and even choice of some variants by him were different. In another study, Labov (1972) investigated the social stratification of (r) in New York City department stores. Linguistic variable (r) is a social differentiator in all classes of New York city speech. The 
results of the study showed clear and consistent stratification of (r) in the three different stores, a low class with low prices, a middle class with reasonable prices and a high class with high prices. The use of (r) by their employees, depending on the social class of the store, was significantly different. In another study by Meechan (1996), the variable contractions of English auxiliaries were investigated. Linguistically contraction is extremely sensitive to phonological factors, therefore, it might be more affected by regional or individual differences in pronunciation. On the other hand, some other factors like formality or informality of the speech setting, the sex of the speaker and other factors could have different effects depending on to what degree they are hidden by phonological effects. The results showed that the nature of the subject was important with personal pronouns most likely to occur before contracted forms and NP least likely. In addition the preceding phonological category was also relevant for the contraction of "is".

\section{METHOD}

\section{A. Participants}

The participants of this study included 60 Iranian university students majoring in English. They were randomly divided into two equal groups of 30, each one consisting of both males and females. In fact, there were four groups of almost 15 in the study: 1. Familiar with the interviewer, female candidates, 2. Familiar with the interviewer, male candidates, 3.Unfamiliar with the interviewer, female candidates and 4. Unfamiliar with the interviewer, male candidates.

\section{B. Procedures}

At the outset of the study, the participants were divided into two equal groups of thirty, odds for group A and evens for group B. The number of males and females were almost equal for both groups. Group A, by chance, was chosen to be interviewed by an unfamiliar interviewer, who was the researchers himself, and group B was chosen to be interviewed by familiar interviewers, who were the subjects' classmates or professors chosen by the candidates themselves and they were with each other, at least, for the last two years. Of course, the familiar interviewers took part in a four-hour session of TTC in order to be made familiar with the IELTS (the International English language Testing System) oral interview framework Which is a four-skill test employed in the selection of prospective non-native speakers of English to universities in such countries as Canada and the UK (O'Loughlin 2002). The version of the speaking sub-test lasts between 10-15 minutes but it took between 15-20 minutes in this study, because in order to get a natural sample of speech, some parts of the official interview were modified; a picture description was used in the third phase of the interview in order to motivate the candidates speak as much as possible. After conducting the interviews, they were tape recorded and transcribed for the language variation analysis.

Thus, some parts of the oral interviews were transcribed and a text analysis (linguistic variant analysis) was done on the interviews in order to find speech variations, which clarified the relationships between different variables of this study in more details. In fact, one of the most natural ways to study the effect of different social variables on the oral performance of the candidates is through studying, their natural speech sample and observing the possible variation that might happen throughout their performance. Variation, here, means" different ways of saying the same thing in different contexts"(Fasold 1989). The design of studying variation in interlanguage and L2 learners is a mode of psycholinguistic experimentation which includes a relevant population of speakers of second language and certain independent variables which are manipulated in the context and production of certain dependent variables in the candidates' interlanguage which is measured by the researchers (Gass, et al 1989). Therefore in this study, the sex of the candidates and their acquaintanceship with the interviewer were independent variables and three dependent variables in the oral data including using "He and She" interchangeably by the candidates through the interviewes, "to be" present form contractions and variable pronunciations of /th/ were manipulated and studied to find any possible relationship between them.

\section{DATA ANALYSIS}

Linguistic Variants Analysis:

This study utilized variationist perspective for the oral interviews data analysis. Therefore, three different items, which were variably used by L2 learners, were selected and the researchers extracted all tokens of the variants to analyze the language behaviors of the subjects in this respect. In this section the findings are presented as follows:

\section{A. Using "He and She" Interchangeably}

A speech variant, investigated here, was the frequency use of "He" instead of "She" and vice-versa. The candidates sometimes used "He" to refer to a female person and "She" to refer to a male one. This variation of speech was supposed to be related to the independent variables of the study, so the frequency use of this variable among the four groups, familiar male and female, unfamiliar male and female, were investigated in order to find any possible relationships between this variable, the candidates' sex and their acquaintanceship with the interviewer. For the first group, familiar male and female, the number of this interchanging use of 'he and she' was significantly different with the next group, unfamiliar male and female. This was shown in the following graph: 


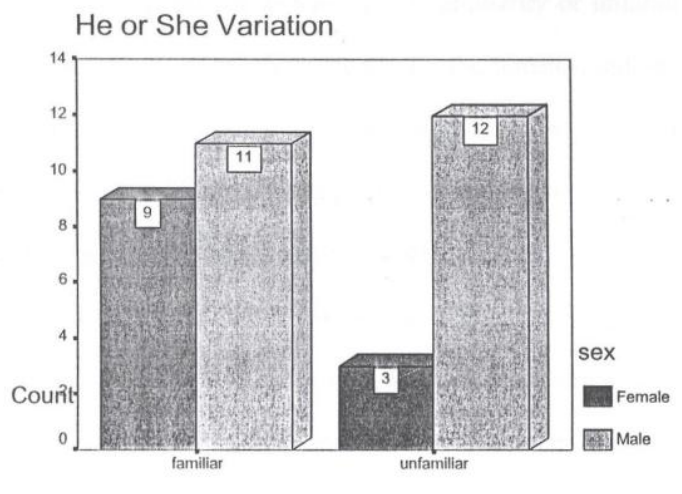

Acquaintanceship

Bar Graph (1)

As shown in Bar graph (1), the use of 'She and He' interchangeably for both familiar and unfamiliar groups, is not different so much (20 for familiar and 15 for unfamiliar). But for the female/male groups, there is a significant difference between the familiar and unfamiliar groups with a frequency use of 11 for familiar male group, 12 for unfamiliar male group, 9 for familiar female and 3 for unfamiliar female group. It shows that the males' use of 'He and She' interchangeably did not depend on the familiarity or unfamiliarity with the test-taker or interviewer, whereas for the females, unfamiliarity with the interviewer has caused a variation in the number of this interchange. To the researchers, this might be due to the speech style and cultural background of the females in the area, they are more sensitive to their speech style in the strange settings. Put it another way, it seems that females are more sensitive to their speech style and linguistic behavior when interacting with unfamiliar people.

\section{B. Contractions of "to be":}

Here the frequency number of contracted forms of "To be" (present form like, I'm, We're, ... ) were considered as a variable and its relationships with the familiarity and unfamiliarity with the interviewer and the sex of the subjects were studied based on statistical procedures. A test of frequency was used here. The male and female groups used 'to be' contractions with different degrees in both familiar and unfamiliar groups.

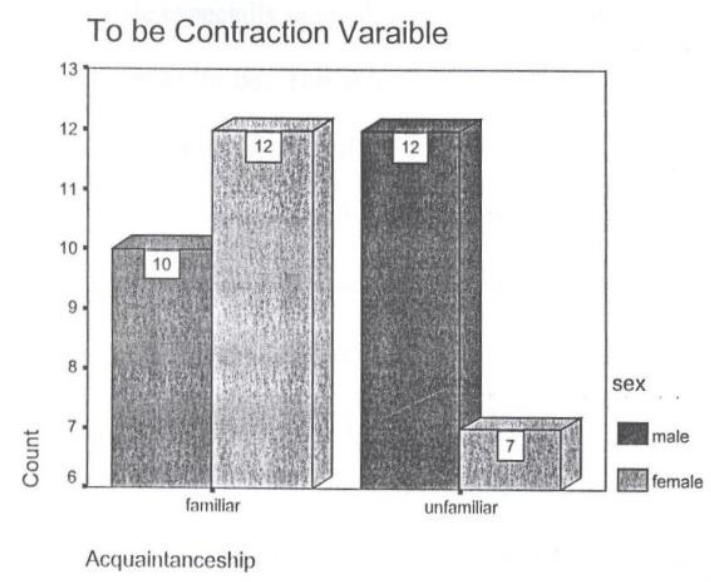

Bar Graph 2

As shown in Bar graph (2), the male groups, both familiar and unfamiliar, do not seem to be so different in using 'to be' contractions with a frequency use of 10 and 12 for familiar and unfamiliar groups. However, this seems to be different in the female groups with 12 and 7 for familiar and unfamiliar groups. In fact, the familiarity and unfamiliarity with the interviewer influenced the female groups more than the male ones. The females, in unfamiliar group, have been much more conservative in using 'to be' contractions than the males in the same situation. This can be explained through the different speech styles (formal, informal) which might be employed by males and females in various situations. Here the females, who seem to be more sensitive to their speech style especially in unfamiliar situations, have tried to use less contracted forms of 'to be'. This is in line with the findings of using 'he and she' as was discussed earlier. On the other hand, there seems not to exist a significant difference between the familiar group with a frequency use of 22 for this variant and the unfamiliar one with 19 . 


\section{Variations of / th / in Pronunciation}

Among Iranian English learners pronunciation of /th/ in words like thank, three ... has three variations, / $/$ / ,/s / and /t/ and sometimes they are all used by the same subject over his/her performance. The first one $/ \Theta /$, a voiceless consonant which does not exist in the mother tongue of the interviewees, can be a source of problem in pronunciation among the learners. The second one / s / and the third variation / $/$ / seem more general among the Iranian learners. In the research data, there are three different variations of this sound including $/ \Theta /, / \mathrm{s} /$, and $/ \mathrm{t} /$, which have been used differently in the male and female groups, both familiar and unfamiliar. The first variation / $/$ / is the native-like one, which was coded as Zero variant here, because it is not considered as a deviation from the target language. The second and the third variations, /s/ and / $/$ / are the deviations from the native one which were used by the interviewees differently as follows:

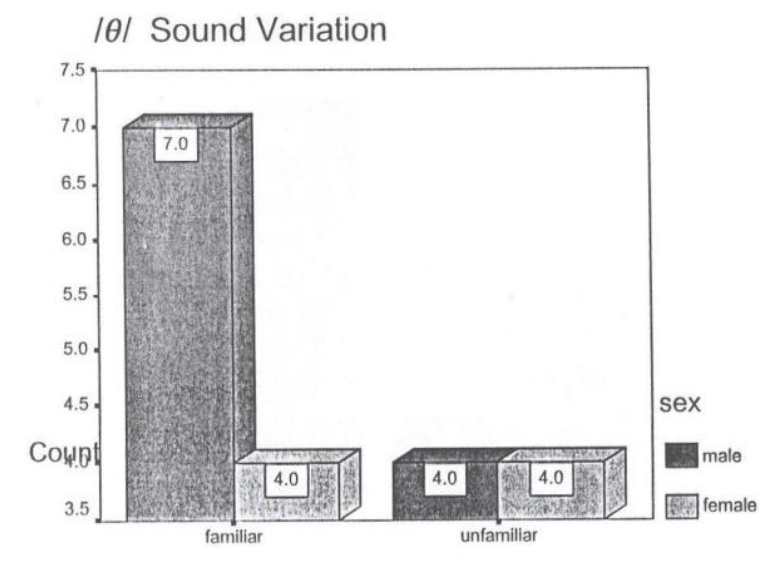

Acquaintanceship

Bar Graph 3

/S/ Sound Variable

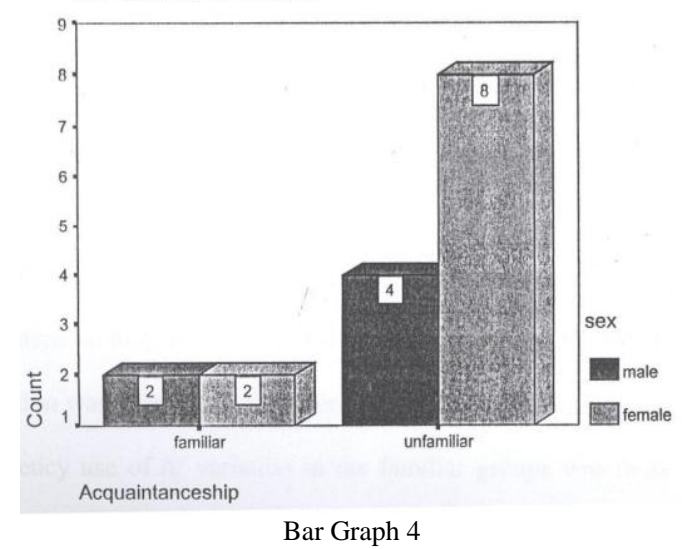

It/ Sound Variable

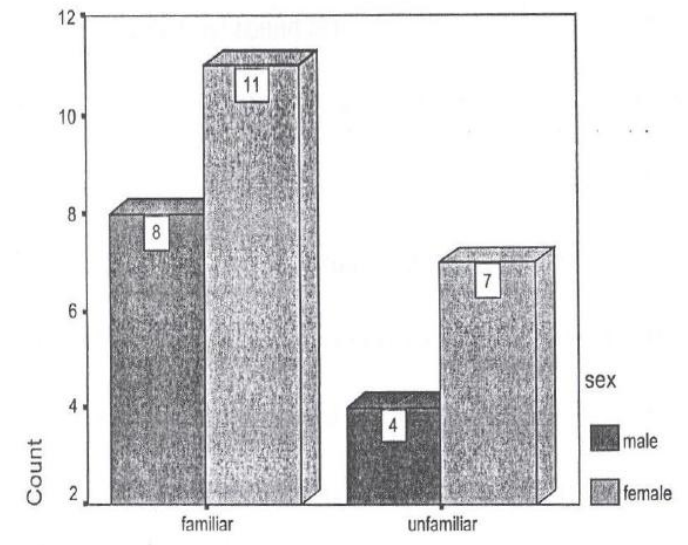

Acquaintanceship

Bar Graph 5 
As shown in the Bar-graphs $(3,4,5)$, the total use of variations of $/ t h /$ in pronunciation includes a frequency number of 18 for $/ \Theta /$, 15 for $/ s /$ and 27 for $/ t$, which are different among the males and females in both familiar and unfamiliar groups. Although the results for the standard variation or pronunciation of $/$ th/ is mixed in both males and females, the use of $/ s /$ and $/ t /$ variations seem to be more organized and follow a kind of pattern. In both male and female unfamiliar groups the frequency of $/ \mathrm{s} /$ variation was more than the male and female in familiar groups. But the frequency use of $/ t /$ variation in the familiar groups was more than the unfamiliar groups. This can be explained through the similarity of the $/ s /$ sound with $/ \Theta /$, sound in comparison with the similarity of $/ t /$ sound with $/ \Theta /$. From the view point of manner and place of articulation of these sounds, it seems that /s/ sound is much more similar to / $/$ /sound than /t/. L2 learners, trying to produce $/ \Theta /$ sound, probably found /s/ sound easier to produce as well as closer to the original sound. In fact, both males and females in unfamiliar groups, trying to produce the original sound, have resorted to the /s/ sound, which is closer to the original one, but familiar groups, since they were supposed not to have the psychological pressure of the unfamiliar interviewers, have resorted to the $/ t /$ sound which, not only exists in their mother tongue but also is more commonly used by L2 English learners in the research area. Moreover, trying to be more formal in unfamiliar settings and the kind of formal instructions the candidates have had, might be other reasons why the interviewees in this study resorted to /s/ sound which seems to be much closer to / $\Theta /$ sound in pronunciation. In general, investigating of this variant showed that both acquaintanceship with the interviewers and the interviewees' gender affected the candidates' performances in the interviews.

\section{CONCLUSION}

For the investigation of variationist perspective on social variables of gender and familiarity in L2 learners' oral interviews, three linguistic variants were extracted and studied through tests of frequencies. The results of the study showed that the females were more conservative and sensitive to their linguistic behavior in unfamiliar settings than the males were. It might be because of the different speech styles the females and males employ when they are in strange settings. In fact, it seems that females are much more formal in their speech than the males are at the similar unfamiliar situations. On the other hand, the relationship between the interviewees' acquaintanceship with the interviewer and their language variation seems to yield mixed results. In some cases, there is a significant difference between the familiar and unfamiliar groups in their use of the language variants ("to be" contractions \& the use of "he and she"), while we might have different results with some other cases ( / th / pronunciations). In general, it seems that language variants (speech variation) were sensitive to the effects of social variables like the interviewees' sex and familiarity with the interviewer. Investigating the possible interaction effect of candidates' gender and their acquaintanceship with interviewers on the candidates' language variation showed that the reactions of males and females might be different to familiar and unfamiliar contexts, but there was no fixed paradigm for this variation and this might be due to the existence of some other factors which affect male and females' performance in different contexts in an oral interview. The effects of the social characteristics of both the interviewer and the interviewees on their oral performance through variationist perspective in this study let the researchers to go far beyond the other studies done in this area and helped them to investigate the possible relationships among the variables more precisely and comprehensively. It is argued that if one is to study the oral performance of the L2 learners, it is not enough to evaluate them only based on their raw scores. Furthermore, it seems that linguistic variation in oral interviews is much more sensitive to the candidates' language variability and their probable performance variations caused by social factors such as their sex, social status, ... than their raw scores in oral interview tests. Therefore, it is suggested to study the L2 learners' oral performances from both variationist and SLA views in order to get a more comprehensive impression of their linguistic behavior.

\section{REFERENCES}

[1] Cholewka, Z. (1997), The influence of the setting and interlocutor familiarity on the professional performance of foreign engineers trained in English as a second language: Spring Vale, Australia.

[2] Fasold, R.W. (1989), Variation theory and language learning. Applied sociolinguistics. Academic Press, New York.

[3] Gass, S., Madden, C., Prston, D. and Slinker, L. (1989). Variation in second language acquisition: Psycholinguistic Issues. Clevedon: multilingual matters LTD.

[4] Gregg, K.R. (1990). The variable competence model of second language acquisition and why it is not. Applied linguistics 11: 364-83.

[5] Labove, W. (1972). The transformation of experience in narrative syntax. Language in the inner city. Philadelphia, UPP.

[6] liu, G. (1991). Interaction and second language acquisition: A case study of a Chinese child' s acquisition of English as a second language. La Trobe university, La Trobe, Australia.

[7] Meechan, M. (1996). In search of the missing link: Copula contraction in Canadian English London, Longman Press.

[8] McNamara, T. (1996). Measuring Second Language Performance: London, Longman Press.

[9] O' Sullivan, B. (2000). exploring gender and oral proficiency interview performance, System 28, 373-88.

[10] O'Sullivan, B. (2002). Learner acquaintanceship and oral proficiency test pair-task performance. Language Testing. 19/3: 27795.

[11] O' Sullivan, B. Porter, D. (1995). Speech style, gender and oral proficiency interview performance. Paper presented at the RELC Conference, Singapore (Net).

[12] O'loughlin, K. (2002). The impact of gender in oral proficiency testing. MA unpublished thesis, The university of Melbourne. 
[13] O'Sullivan, B. (2000). The effect of candidates acquaintanceship on OPI performance. Language Testing 19, 277-295.

[14] Porter, D. \& Shen Shu Hang. (1991). Sex , status and style in the Interview. Ahrhus, pp. 111-128.

[15] Porter, D, (1991b). Affective factors in the assessment of oral interaction: Gender and Status. Anthology Series 25, pp. 92-102.

[16] Porter, D. (1991a). Affective factors in language testing, Language Testing in the 1990s, London, pp. 32-40.

[17] Tannen, D. (1990). You just do not understand: Women and men in conversation. William Morrow Press, New York.

[18] Tarone, E. \& Liu, G.Q.(1989). Situational context, variation and second language acquisition theory. Oxford University Press.

[19] Tarone, E. (1995). A variationist framework for SLA research: Examples and pedagogical insights. In Eckman, et. al. Second language acquisition theory and pedagogy. Mahwah, NJ: Lawrence Erlbaum. University of Minnesota.

[20] Young R. (1988). Ends and means: Methods for the study of interlanguage variation. Multilingual Matters LTD.

Mohiadin Amjadian is a faculty member at Kurdistan medical university. He got his MA in TEFL at Tarbiat Modares University. $\mathrm{He}$ is interested in ESP, language testing and material development.

Saman Ebadi is a PhD candidate of TEFL at Allamaeh Tabatabei University, Tehran, Iran. His areas of interest are sociocultural theory, dynamic assessment, CALL, CMC, language acquisition, and syllabus design. He has presented in different national and international conferences on ELT and published articles in scholarly journals. 